\title{
Measuring the Effectiveness of a Series of Workshops Focused on the Retention of Underrepresented Engineering Faculty
}

\author{
Norma Jean Mattei, Ph.D., P.E. \\ University of New Orleans
}

\begin{abstract}
With a workforce that is heavy with engineers nearing retirement age and an engineering undergraduate population growth rate that is fairly flat, administrators will have to focus more and more on recruitment and retention. Women and minorities have long been underrepresented in engineering and are a potential source of future engineers. A diverse faculty would, of course, be an asset in getting and keeping a more diverse student body. However, the pool of women and minority engineering faculty is quite limited. These faculty usually do not have the benefit of similar mentors and peers at their institutions on whom they can rely for coaching and support. To help level the playing field, a series of three-day workshops have been sponsored by the National Science Foundation for the past decade, occurring every other year since 1995. Participants of these workshops are women and minority engineering faculty who are in the first three years of a tenure-track appointment and $\mathrm{PhD}$ candidates actively looking to become educators. The benefits of the workshops include enhanced participant awareness of research and funding opportunities and what is required to be successful in academe (teaching, publishing, outreach, etc.); diversification of participants' research program goals; and development of a network of mentors and peers who have encountered similar challenges in advancing within academe (specifically within their own technical fields). In order to access the success of these workshops, participants were given a pre-workshop and a post-workshop survey. The results of these surveys indicate that the workshops' goals are being met. The workshop and the results of the surveys will be discussed in detail.
\end{abstract}

\section{Introduction}

Engineering, despite advances in the past several decades, is still primarily a white male dominated profession. In promoting diversity, having a similar role model helps in student retention of underrepresented groups. Engineering faculty are the first role models that many students are exposed to. However, engineering faculty are even less diverse than the engineering workforce [5]. In 2001, 16\% of the science and engineering doctorates were awarded to women (up from 12\% in 1997). Blacks only earned 3\% and Hispanics earned almost $4 \%$ of all science and engineering doctorates in 1997, but these percentages declined in 2001. Accordingly, the pool of potential female and minority engineering educators is very small. Should it be important to the profession that these female and minority doctoral students be retained in academia as engineering educators? 
The National Science Foundation (NSF) has sponsored a series of workshops. This paper describes a series of three-day workshops designed to foster technical and intellectual exchange among Ph.D. level, female and minority engineers who are or desire to be engineering educators. The intent of the workshops is to instill in its participants the sense of a technical community in which they can thrive and to which they can contribute. In keeping with NSF goals, the workshops were designed to encourage retention and advancement of qualified women and underrepresented minority engineers in pursuit of scientific and engineering advances. The workshops were held in Washington D.C. (Arlington, VA), most recently at the NSF Stafford II Conference Center adjacent to the NSF headquarters. The first workshop was held in the fall of 1995. Subsequent workshops occurred every other year, with the next one planned for September of 2005.

The paper will first explore one reason why it is important to have a diverse engineering faculty. The general program for all workshops will then be outlined. Following this discussion are the results of the pre-workshop and post-workshop surveys of the 2003 participants. The surveys' questions were selected to probe the participants about their knowledge of issues critical to their success as engineering educators. Comparison of the two surveys' results indicates that participants gained much knowledge as a result of attending the workshop. Hopefully this increased knowledge will ultimately result in the retention of these women and minority engineering faculty.

\section{Background}

According to the U. S. Bureau of Labor Statistics, overall engineering employment is expected to grow more slowly than the average for all occupations during 2002 to 2012 [1]. Despite this, overall job opportunities in engineering are expected to be good because the number of engineering graduates should be in rough balance with the number of job openings over this period. Employment of mining, petroleum, nuclear, and geological engineers is projected to decline, while other engineering disciplines, such as environmental engineering, are thought to have much faster than average employment growth.

Engineering enrollments nationwide peaked in 1983. They have since decreased by about $20 \%$. According to the National Science Foundation, there were 392,198 students enrolled in undergraduate engineering programs in 1987 [8]. In 1997, only 365,358 students were enrolled in undergraduate engineering programs and the trend is still downward but has somewhat leveled off. The number of engineering master's degrees granted per year increased to a high in 1994 [6]. Since then, those numbers have also dropped. The number of science and engineering doctorates conferred annually by U. S. universities reached a peak in 1998 and have declined since then. The rise in the number of doctorates through 1998 largely reflected an increase in the number of foreign U. S. doctorate degree recipients. In fact, foreign-born engineers and scientists make up more than one fourth of the engineering and science doctorate holders doing research in both academia and industry.

As result of the September 11 terrorism, the United States may permit immigration at only a very carefully monitored trickle. This could seriously depress the supply of foreign students and 
engineers and increase the need for engineering schools to recruit and retain domestic students. Retention is a problem at most engineering schools, even under the best of circumstances, and is a serious challenge in an "insular" United States [4]. Decreases in immigration could also severely deplete the pool of foreign graduate students on which U.S. research relies so heavily to serve as research and teaching assistants. Most U.S. students are reluctant to pursue the Ph.D., partly because of the considerable costs and the lure of high salaried positions in industry that do not require a doctorate. The data listed in Table 1 demonstrates the decline in temporary visas applied for and granted to students and high-skill visitors in 2001 through 2003.

Table 1: Increase in refusal visa applications by the U. S. State Department [6]

\begin{tabular}{ccccccc} 
& \multicolumn{2}{c}{ Student $(\mathrm{F}-1)$} & \multicolumn{2}{c}{ Visitor $(\mathrm{J}-1)$} & \multicolumn{2}{c}{ Other high skill visas } \\
Year & Applications & \% refused & Applications & \% refused & Applications & \% refused \\
\hline 2001 & 399,988 & 27 & 279,524 & 8 & 248,421 & 10 \\
2002 & 346,419 & 33 & 278,598 & 11 & 203,551 & 12 \\
2003 & 325,844 & 35 & 295,624 & 16 & 200,233 & 18
\end{tabular}

\section{A changing population}

A review of U.S. census data indicates changes in minority populations. During the 1990s, the combined populations of African Americans, Native Americans, Asians, Pacific Islanders, and Hispanics/Latinos grew at 13 times the rate of the non-Hispanic white population. The data in Table 2 summarizes the demographic statistics by gender and race/ethnicity. Table 2 data also shows the contrast in gender and racial/ethnic background in the population of the United States $[10,11]$ and the makeup of engineering bachelor degree recipients for 2002-2003 [7]. Note that the data for engineering BS degree recipients in the listed in the fifth column of Table 2 does not show all degree recipients $(7.1 \%$ of these graduates listed their ethnicity as "Other". The information listed in Table 3 gives the demographic statistics by age.

Most notable is the increase in the number of Hispanic Americans, which now surpasses the African American population. The U.S. Hispanic population grew 58 percent between 1990 and 2000. If current trends continue, Hispanic Americans will account for 17 percent of the U.S. population by 2020, and African Americans 12.8 percent. The percentage of whites will decline from the 2000 value of 75.6 percent to 63.7 percent. Looking further into the future, by 2050 , almost half of the U.S. population will be non-white [9]. Thus, in 2020 and beyond, the engineering profession will need to draw more students from sectors that traditionally have not been well represented in the engineering workforce. How can we, as a profession, make engineering more attractive to this diverse source of future engineers? 
Table 2: General demographics versus undergraduate engineering demographics, with 2020 projections $[7,9,10, \& 11]$

\begin{tabular}{lcccc}
\multicolumn{1}{c}{ Gender/ethnicity } & US 1990 & US 2000 & US 2020 & Engr. 2003 \\
\hline Male & $48.8 \%$ & $49.1 \%$ & $48.9 \%$ & $79.6 \%$ \\
Female & $51.3 \%$ & $50.9 \%$ & $51.1 \%$ & $20.4 \%$ \\
Caucasian & $75.6 \%$ & $69.1 \%$ & $63.7 \%$ & $68.3 \%$ \\
African-American & $11.7 \%$ & $12.1 \%$ & $12.8 \%$ & $5.0 \%$ \\
Am. Indian & $0.7 \%$ & $0.7 \%$ & $0.8 \%$ & Not available \\
Asian-American & $2.8 \%$ & $3.7 \%$ & $5.7 \%$ & $14.1 \%$ \\
Hispanic & $9.0 \%$ & $12.5 \%$ & $17.0 \%$ & $5.5 \%$
\end{tabular}

As shown by Table 3, the U.S. population is aging. As the engineering workforce ages, more engineering graduates will be needed to fill existing positions, both in academia and industry.

Table 3: General demographics by age, 2020 numbers are projected [9]

\begin{tabular}{|c|c|c|c|}
\hline Age & 1990 & 2000 & 2020 \\
\hline Under 18 & $25.6 \%$ & $25.7 \%$ & $23.7 \%$ \\
\hline $18-64$ & $61.9 \%$ & $61.9 \%$ & $59.7 \%$ \\
\hline 65 and over & $12.6 \%$ & $12.4 \%$ & $16.5 \%$ \\
\hline
\end{tabular}

\section{Role models}

One way to increase diversity of the student population is to foster a diverse faculty. According to Kim Parker Brown, an African-American woman civil engineer, "When I was younger, I felt that it really made a difference to be around someone who looked like me and made me feel comfortable. These perceptions were there, although my parents taught me that I should not worry about fitting in with everyone and should simply work at being the best civil engineer I could be." To a young person, fitting in and having a role model are very important. Diversity in engineering faculty is needed in order to provide all students with appropriate role models.

This is not true only for students. A study by the Catalyst Research Group [2] on minority women in the general workplace surveyed 1700 African-American, Hispanic and AsianAmerican female managers. The study found that $22 \%$ of the women surveyed intended to quit their companies. Although most had graduate degrees, many found that they were not moving up in their corporations. 
Key concerns include:

- $47 \%$ don't have an influential mentor,

- $40 \%$ site lack of informal networking with influential colleagues,

- $29 \%$ lack company role models of the same race/ethnic group, and

- $28 \%$ don't get high visibility projects.

Can the provision of role models help in the retention of underrepresented students, engineers, and educators? Some engineering schools think so. The University of Texas at San Antonio's (UTSA) College of Engineering's faculty is 20-25\% minority. UTSA's ultimate goal is for minorities to comprise half of the faculty, so that the faculty makeup will mirror that of the surrounding community [3].

\section{Retention of role models: the engineering educator}

NSF recently funded several workshops that have targeted women and minority engineering educators. The first workshop was held in 1995, with subsequent workshops held every other year. These workshops were designed to uncover and perhaps address problems that these women and minority faculty have found in beginning their careers. The intent of the workshops was to instill in the participants a sense of belonging within a technical community in which they can succeed and make essential contributions. Participants at each of the 2001 and 2003 workshops were women or minority faculty ( 55 participants) and faculty candidates ( 25 participants). Faculty participants were currently employed in tenure track teaching and research faculty positions. Forty-five were in the first four years of their academic careers and will be actively trying to develop research programs. Ten were senior tenured faculty, with a minimum of six years of experience. Ph.D. candidate participants were in the final year of their Ph.D. program and actively pursuing tenure track faculty positions. Workshop participants were selected to include a broad range of race, gender, ethnic origin, technical expertise, geographic location and university affiliation.

\section{Description of the Workshop Series}

The first workshop, in 1995, was held for forty engineering educators conducting research in the areas supported by the Dynamics Systems and Controls Program of the Civil and Mechanical Systems (CMS) Division. Feedback from participants was consistent in indicating that the information provided on research, education, and funding was quite beneficial and perhaps more significantly, that the opportunity for meeting and getting to know fellow female and minority colleagues and learning about their research activities in a similar technical area through the workshop setting was extremely valuable. The workshop was expanded in 1997 to approximately 100 engineering educators conducting research in the areas supported by CMS. In 1999, both CMS and the Bioengineering \& Environmental Systems Division (BES) sponsored the workshop, and it was again expanded to approximately 120 participants. About 90 of the participants had research interests supported by CMS and about 30 had interests supported by BES. Although the 1999 workshop participants experienced more interdisciplinary interactions, they lost some of the personal interactions that occurred in the previous workshops because of the increased number of participants. In addition several of the meeting rooms were crowded 
with 100-120 participants. With this in mind, the 2001 and 2003 workshops were restricted to eighty participants conducting research in the areas supported by CMS, drawing more heavily from the content of and the feedback about the 1995 and 1997 workshops.

The 1995 workshop consisted of six formal sessions spread over a 2-1/2 day period and two halfday technical tours of national research laboratories. The workshop started with government speaker presentations from the NSF engineering directorate, the Air Force Office of Scientific Research (AFOSR), the Office of Naval Research (ONR), NASA, and the NSF Division of Undergraduate Education. Each speaker summarized the emphasis of their agency's programs and described opportunities available for funding from their organizations. The next three sessions focused on the Dynamic Systems and Controls Program technical areas of: 1) controls, 2) vibrations and acoustics, and 3) dynamics diagnostics. These sessions started with a keynote speaker who presented an overview of prominent research challenges in their emphasis area. The keynote speakers were selected because of their outstanding contributions to their field of expertise and for their reputation as excellent female/minority role models. For the second part of these three sessions, each workshop participant presented a ten minute summary of their current research interests and activities. This increased fellow participants' awareness of the rich diversity of related opportunities for involvement in dynamics and controls research and stimulated discussion related to collaborative research endeavors. Lastly, two "working sessions" were held that were devoted to small group discussions (8-10 participants) of topics selected by the participants. The topic areas included research and funding concerns, balancing of family and career, and diversity issues.

The workshop also included technical tours of laboratories and on-going research activities at the National Institute of Standards and Technology (NIST), The Naval Surface Warfare Center (NSWC), and the Naval Research Laboratories (NRL). In addition to the technical benefits of visiting these labs, the tours provided an informal environment that promoted socializing, networking, and generally getting to know one-another. (One interesting note is that only the bus ride to the first tour was fairly quiet; the subsequent four bus rides were all quite loud with the full gambit of conversations related to technical and personal issues taking place!) Both networking and socializing among participants was strongly encouraged and facilitated by the scheduling of the working sessions, the informal atmosphere of the tours, meals, and evening free time.

The workshops that followed the 1995 workshop have incorporated a few changes and additions. Participants now select only one tour. A panel of deans and department chairs was added to discuss the expectations of administration. A presentation by representative from a professional society, such as the American Society of Civil Engineers (ASCE), and American Society of Engineering Education (ASEE) was also added. These presentations gave participants information regarding what these organizations have to offer young engineering educators (summer institutes, fellowships, leadership opportunities, etc.).

\section{Objectives of the workshop series}

There were there specific workshop goals. The first goal was to foster technical and intellectual exchange among Ph.D. level, women and minority engineers who are or desire to be engineering

"Proceedings of the 2005 American Society of Engineering Education Annual Conference \& Exposition Copyright (C) 2005, American Society of Engineering Education” 
educators. The second goal was to instill in its participants the sense of a technical community in which they can thrive and to which they can contribute. The final goal was to increase participant awareness of research and funding opportunities.

There was three envisioned short-term significance and benefits of the workshop. One benefit was enhanced participant awareness of research and funding opportunities and what is required to be successful in academe (teaching, publishing, outreach, etc.). The second benefit for attendees of the workshops was diversification of participants' research program goals. The final and perhaps most significant benefit would be the development among participants of a network of mentors and peers who have encountered similar challenges in advancing within academe (specifically within their own technical fields).

There long-term significance and benefits of the program were envisioned. The first was improved retention of women and underrepresented minority engineers as active researchers, mentors, and instructors in engineering education. Secondly, it is hoped that attendees develop an infrastructure of colleagues who work in similar fields of research that has a rich diversity, through contacts made at the workshops. Ultimately, it is envisioned that there will be increased diversity in the undergraduate engineering student population as a result of a more diverse engineering faculty.

\section{Assessment of workshop effectiveness}

The effectiveness of each workshop was measured through the use of a pre-workshop survey and a post-workshop survey. Results of the 2001 and 2003 workshops surveys will be reported herein. The first survey, the pre-workshop survey, was administered at registration to the workshop. Fifty seven of the participants of the 2001 workshop completed the pre-workshop survey. Seventy one of the participants from the 2003 workshop completed the first survey. The second survey was given to the participants at the end of the last session of the workshop. Fifty two participants of the 2001 workshop and fifty four participants of the 2003 workshop completed the second survey.

\section{Results of the survey}

Table 4 lists the results of the two surveys of the 2001 and 2003 workshops. A comparison of pre-workshop and post-workshop surveys results indicate that the workshops were successful in increasing participant's awareness of research, teaching, and tenure issues. However, it is very hard to measure the impact of this series of workshops on the successful retention of these engineering educators.

Respondents could respond to the eight questions on each survey using the scale:

- $1=$ not at all (very low),

- 2 = a little (low),

- 3 = somewhat (some),

- 4 = quite a bit (high), and

- $5=$ completely (very high). 
It should be noted that data from the 2001 workshop was limited to aggregate data lumped into groups. The survey results from the 2003 workshop were available in their entirety, so that a more in-depth comparison of each topic from the 2003 workshop surveys could be done.

Table 4: Assessment of Outcomes of the 2001 and 2003 Workshops Based on Pre- and PostWorkshop Surveys

\begin{tabular}{clcccc} 
& & \multicolumn{3}{c}{ \% Responses: high or very high awareness } \\
\cline { 3 - 6 } Question \# & \multicolumn{1}{c}{ Question Topic } & Pre-Workshop & & Post-Workshop \\
& & 2001 & 2003 & 2001 & 2003 \\
\hline Q1 & Understanding of academic career issues & $54 \%$ & $39 \%$ & $94 \%$ & $91 \%$ \\
Q2 & Awareness of career expectations and demands & $67 \%$ & $46 \%$ & $87 \%$ & $89 \%$ \\
Q3 & Awareness of tenure demand (teaching, research, publications) & $74 \%$ & $54 \%$ & $87 \%$ & $87 \%$ \\
Q4 & Awareness of funding \& community service perspective & $40 \%$ & $31 \%$ & $71 \%$ & $93 \%$ \\
Q5 & Awareness of integration of research \& education & $40 \%$ & $25 \%$ & $62 \%$ & $72 \%$ \\
Q6 & Awareness of funding opportunities & $21 \%$ & $27 \%$ & $69 \%$ & $94 \%$ \\
Q7 & Awareness of the characteristics of a strong proposal & $33 \%$ & $25 \%$ & $73 \%$ & $74 \%$ \\
Q8 & Awareness of important technology growth areas & $25 \%$ & $21 \%$ & $74 \%$ & $46 \%$
\end{tabular}

In general, pre-workshop survey results from the 2001 workshop respondents indicate a higher level of awareness of the respondents in all areas except one when compared to pre-2003 workshop survey results. The administration of the pre-workshop surveys was not different from 2001 to 2003, nor was the method by which workshop participants were selected or the makeup of the participants of each workshop. Data is available for the two workshops only, so no trend can be established except that the participants of the 2001 workshop began the workshop with a higher awareness level in seven of the eight areas than participants beginning the 2003 workshop.

There was little variation in 2001 and 2003 post-workshop survey responses except in three areas. Results of questions four and six indicate that there was a marked increase in awareness of 2003 workshop participants when compared to 2001 workshop participants. Question four asked about awareness of funding and community service, from the perspective of administration. Question six questioned the participants about their awareness of funding opportunities. The 2003 workshop program included some modifications to that of the 2001 workshop. These modifications included the addition of department chairs in the Dean's Panel. The department chairs were much more specific in speaking about their perspectives on both funding and service. Another change was that keynote speakers were asked to not only provide a presentation on their recent research, but to personalize the talk by including an overview of their careers and information on personal/family decisions. Speakers from ASCE and ASEE were also added. The ASCE presentation included information on the submission process of articles to ASCE journals, a topic of great interest to untenured faculty. Information was also given on the availability of ASEE summer research fellowships for young faculty. 
Question eight post-workshop results indicate that 2001 participants were more aware of important technology growth areas than 2003 workshop participants. The "line-up" of workshop presenters from government agencies did not vary from 2001 to 2003 . The author speculates that this decrease in awareness from 2001 to 2003 may indicate the uncertainty associated with the general decrease in funding levels that has occurred since 2001 of most government agencies in CMS-related research areas due to the war in the Middle East.

\section{Academic career issues}

The data in Chart 1 shows a comparison of the results of the academic career issues part of the survey. Participant awareness of the broad range of academic issues increased as a result of the workshop.

\section{Academic Career Issues Range of academic issues}

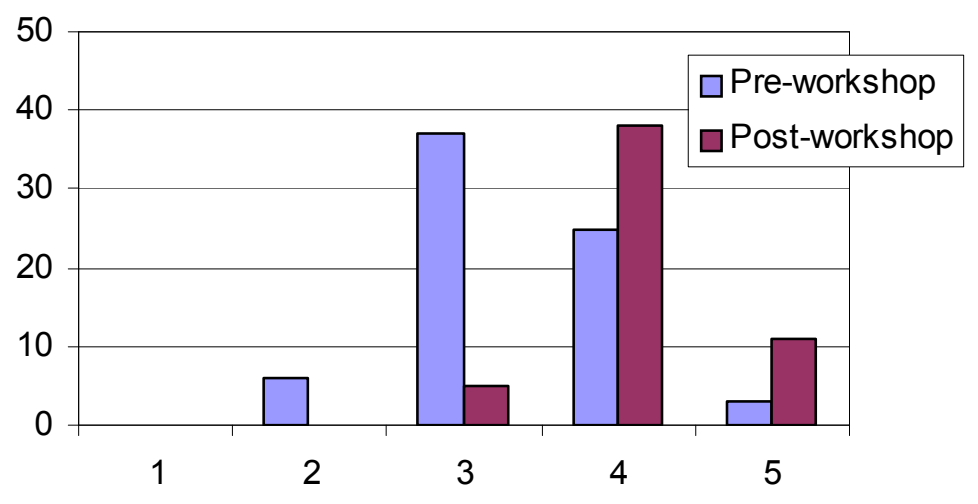

Chart 1: Comparison of Pre-workshop and Post-workshop results - Q1

\section{Expectations from administration}

Data in Charts 2, 3, and 4 give the comparison of results for questions regarding expectations of administration for young engineering faculty. Trends in the data of the three charts indicate that participant awareness increased due to the workshop in regard to career expectations and tenure demands (teaching, research, and publications), and funding and service perspectives. 
Expectations from administration

Career expectations and demands

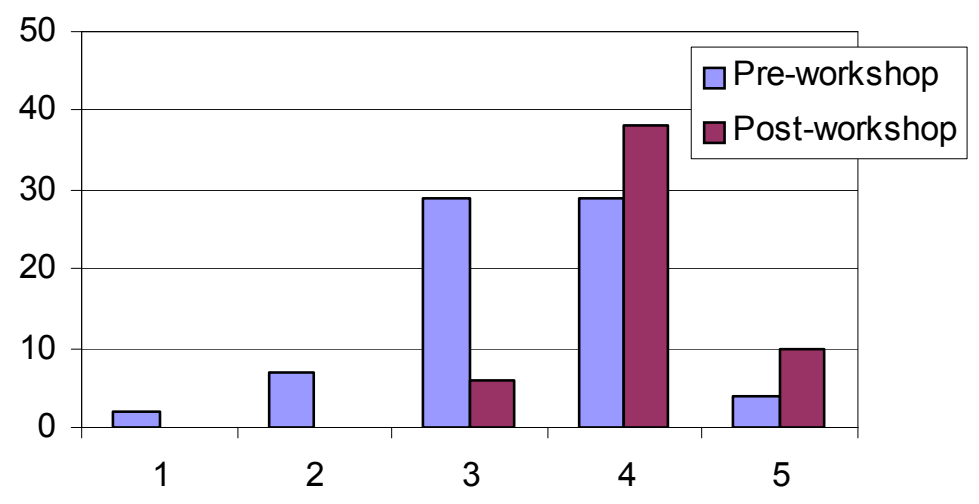

Chart 2: Comparison of Pre-workshop and Post-workshop results - Q2

\section{Expectations from administration \\ Tenure demands}

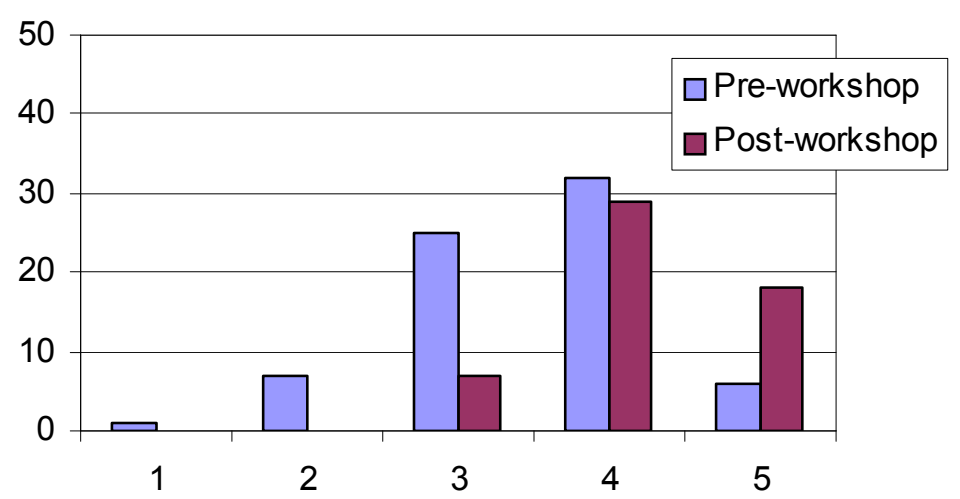

Chart 3: Comparison of Pre-workshop and Post-workshop results - Q3 


\section{Expectations from administration \\ Funding \& service perspectives}

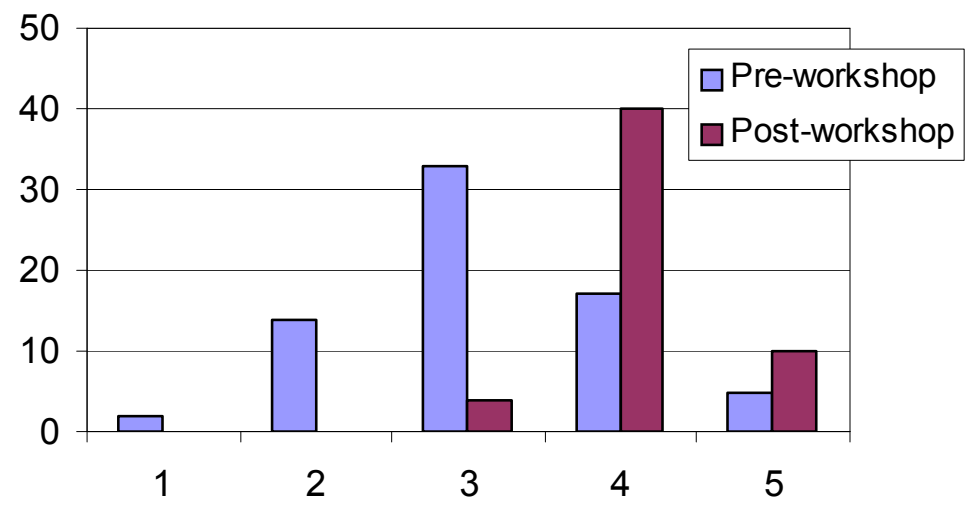

Chart 4: Comparison of Pre-workshop and Post-workshop results - Q4

\section{Education and research opportunities}

The data in Charts 5, 6, 7 and 8 show the results of a comparison of pre-workshop and postworkshop survey responses to education and research opportunity related questions. Information is these charts indicate that the workshop participants' knowledge of education and research opportunities increased due to workshop attendance in the areas of integration of research and education, funding opportunities, knowing the characteristics of a strong proposal, and important technology growth areas.

\section{Education \& Research Opportunities Integration of research \& teaching}

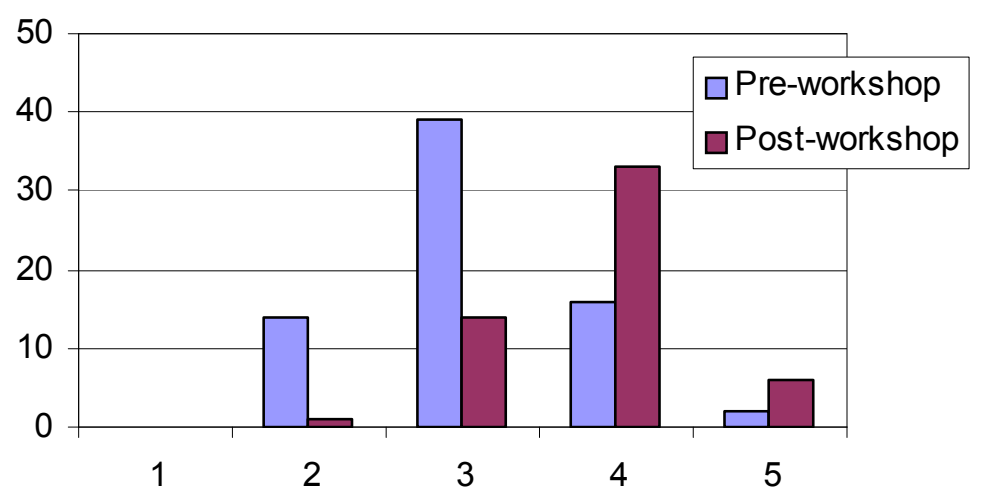

Chart 5: Comparison of Pre-workshop and Post-workshop results - Q5 


\section{Education \& Research Opportunities Funding Opportunities}

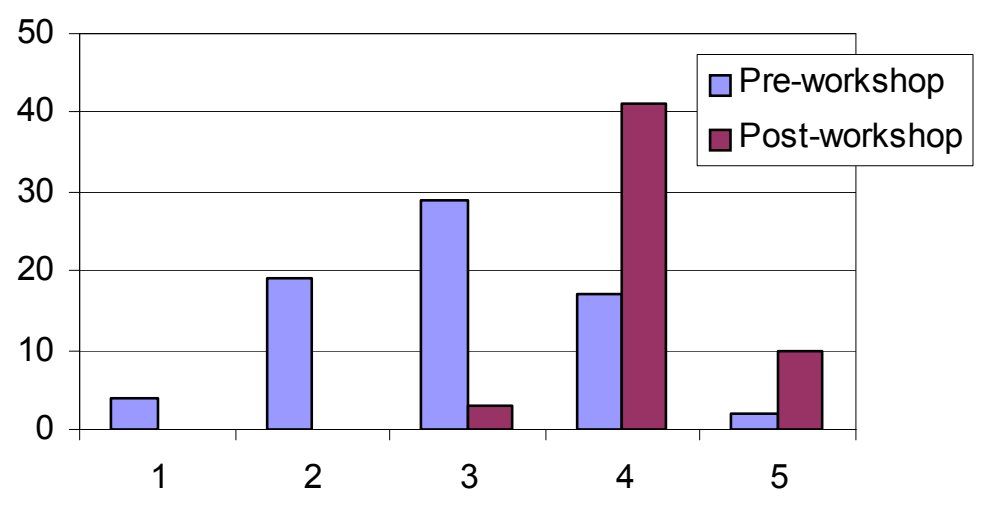

Chart 6: Comparison of Pre-workshop and Post-workshop results - Q6

\section{Education \& Research Opportunities Characteristics of strong proposals}

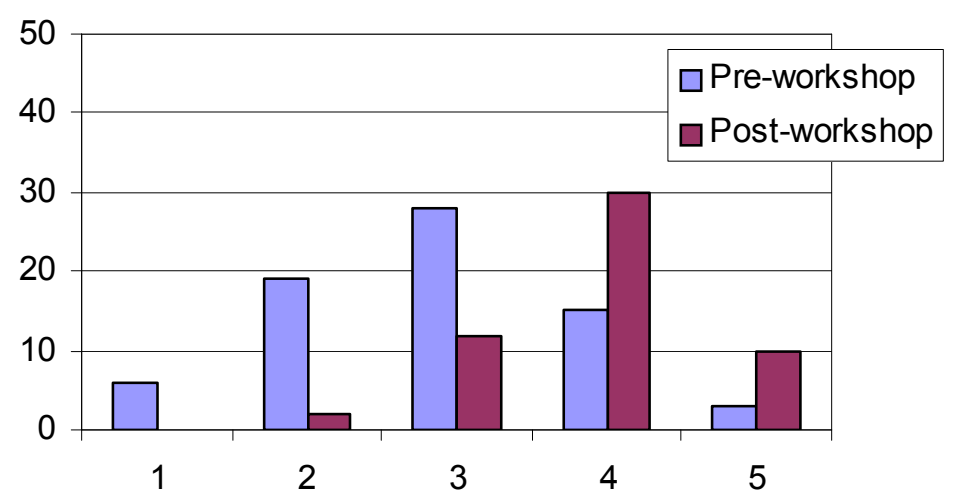

Chart 7: Comparison of Pre-workshop and Post-workshop results - Q7 


\section{Education \& Research Opportunities Important technology growth areas}

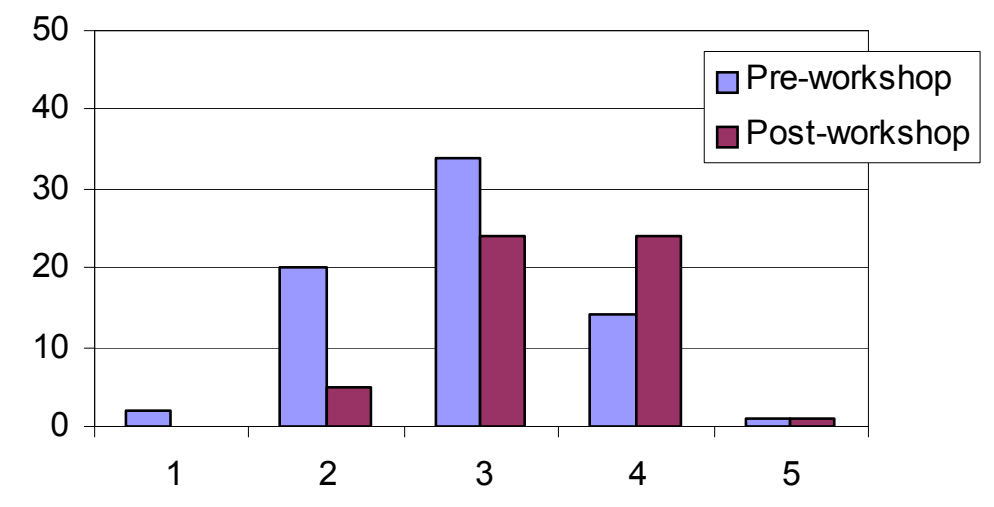

Chart 8: Comparison of Pre-workshop and Post-workshop results - Q8

\section{Conclusions}

With the pool of foreign-born students and engineers restricted and the U.S. population becoming increasingly diverse, women and minority high school students could be a source of future engineers. One way to attain a more diverse student population is to provide appropriate role models for these students. A diverse faculty would provide these role models. Thus it is important to recruit and retain female and minority engineering educators. As the number of women and minority engineering educators increases, there should be a corresponding increase reflected in the makeup of the undergraduate engineering student pool.

In order to help retain women and minorities in engineering education, a workshop sponsored by NSF has been held every other year since 1995 . The objective of the workshops is to educate these underrepresented educators on issues that can help or hinder them in their quest for a tenured position in academia. The intent of the workshops is to uncover and perhaps address problems that these female and minority faculty have found in beginning their careers. A comparison of the results of pre-workshop and post-workshop surveys of the women and minority engineering educator respondents of the 2001 and 2003 workshop surveys indicate that the workshops are successful in increasing participant awareness on issues critical to success in academia. The comparison of the 2001 and 2003 workshop results indicated that slight changes in the format of the 2003 workshop increased participant awareness in several areas. These modifications included:

- Inclusion of department chairs in the Dean's Panel,

- Keynote speakers were asked to provide a presentation on their recent research, but to also personalize the talk by including an overview of their careers and information on personal/family decisions,

- Addition of speakers from ASCE and ASEE with information on the submission process of articles to ASCE journals and availability of ASEE summer research fellowships for 
young faculty.

It should be noted that there was a marked decrease in awareness of the 2003 workshop attendees when compared to the 2001 attendee awareness levels in one area, technical growth areas, although there was no change in the format of the workshops in this area. This may be attributed to a general decrease in funding levels of most government agencies in CMS-related research areas due to the war in the Middle East.

In closing, the workshops also allowed participants to list problems and comments associated with being a female or minority engineering educator. Problems cited most by those women and minority engineering educators who responded to the survey include:

- more service work than other faculty (which is not rewarded in tenure and promotion)

- feeling isolated

- not being part of the network

- not being taken seriously as a instructor/researcher

It is the intent of the workshop series to increase the number of women and minority engineering faculty so that eventually underrepresented engineering educators will not be so unrepresented.

\section{References}

1. Bureau of Labor Statistics, U.S. Department of Labor, Occupational Outlook Handbook, 2004-2005 Edition

2. Catalyst Research Group, "Minority women in the workplace." The Associated Press, Times Picayune, Section C, February 10, 1998

3. Grose, T., "Engineering's New Look", ASEE Prism, February, 2005

4. National Academy of Engineering, "The Engineer of 2020 - Visions of Engineering in the New Century", 2004

5. National Center for Education Statistics, "Digest of Education Statistics", 2003

6. National Science Board, “Report: Science and Engineering Indicators - 2004.", 2004

7. National Society for Engineering Education, “A New Look at Engineering”, 2003 Engineering Profile, 2002-2003

8. National Science Foundation, "Report: women, minorities and persons with disabilities in science and engineering: 2000", 2000

9. U.S. Census Bureau, U. S. Census Bureau National Population Projections. Available online at www.census.gov/population/www/projections/natproj.html, 2002

10. U.S. Census Bureau, United States, Database, 1990

11. U.S. Census Bureau, United States, Database, 2000

NORMA JEAN MATTEI is an associate professor in the Civil and Environmental Engineering Department of the University of New Orleans. She teaches structural engineering analysis and design classes. Her research areas include diversity, experimental structural testing and materials testing, engineering ethics and residual stress measurement using speckle pattern interferometry. 